\title{
Preparation and Characterization of Biodiesel Produced from Recycled Canola Oil
}

\author{
Xiaohu Fan*, Rachel Burton and Greg Austic
}

Piedmont Biofuels Industrial, Pittsboro, NC 27312, USA

\begin{abstract}
The purpose of this paper is to evaluate the feasibility of using recycled canola oil as raw material to produce ASTM standard biodiesel. Two-step reaction, acid-catalyzed esterification followed by alkali-catalyzed transesterification, was performed. The high level of free fatty acids ( FFA) in the recycled canola oil was reduced to less than $1 \%$ by acidcatalyzed esterification with 40/1 molar ratio of methanol to FFA in the presence of $5 \%(\mathrm{v} / \mathrm{v}$, based on FFA) sulfuric acid. Further alkali-catalyzed transesterification was carried out at $6 / 1$ molar ratio of methanol to oil and $1 \%$ (wt $\%$, based on oil weight) potassium hydroxide. The characterizations of produced biodiesel showed that it met the ASTM D 6751 with respect to the kinematic viscosity at $40{ }^{\circ} \mathrm{C}$, acid number, flash point, water and sediment, cold soak filtration test, oxidation stability, free and total glycerin etc. At the same time, the properties of by-product crude glycerol, such as flash point, moisture by Karl Fisher, ash, glycerol content, were also characterized, which can facilitate further glycerol purification and expand its applications, thus enhancing the overall profitability of the biodiesel production process.
\end{abstract}

Keywords: Biodiesel, characterization, esterification, glycerol, transesterification, recycled canola oil.

\section{INTRODUCTION}

In a search for new energy sources, much attention is focused on biomass as a reliable and renewable source that is able to satisfy a significant part of the energy demands. Currently, biodiesel is considered a real alternative to diesel fuel due to its following advantages.

1. It can reduce the dependence on crude oil foreign imports and enhance the energy security. 2. It has favorable energy return on energy invested. 3. It can reduce greenhouse emissions and lower harmful emissions. 4. It is biodegradable, nontoxic, and renewable (when ethanol is used instead of methanol). 5. It can help improve rural economies since the agricultural surplus is used as raw material.

Though biodiesel is technically feasible and environmentally acceptable, it should be noted that it is not economically competitive. The high cost of virgin vegetable oil is the most important issue in the economic evaluation of the biodiesel process [1]. Reducing the cost of the feedstock is necessary for biodiesel's long-term commercial viability. In order to achieve production cost reduction and make biodiesel more competitive with petroleum diesel, low cost feedstocks, such as non-edible oils, waste vegetable oils could be used as raw material.

At present, waste oils are sold commercially as animal feed. However, since 2002, the European Union (EU) has enforced a ban on feeding these mixtures to animals to prevent the return of harmful compounds back into the food chain through the animal meat. In fact, most of the used cooking oil is poured into the sewer system of the cities. This

*Address correspondence to this author at the Piedmont Biofuels Industrial, 220 Lorax Lane, P.O.Box 661, Pittsboro, NC 27312, USA; Tel: 919-3218260; Fax: 919-321-6769; E-mail: xfan@biofuels.coop will contribute to the pollution of rivers, lakes, seas and underground water, leading to the negative effect on the environment and human health. Therefore, the disposal of waste oils in a safe way is required since it may contaminate the environment. The utilization of waste oils for producing biodiesel is one of the efficient and economical approaches to solve this.

Considerable research has been conducted to investigate the production of biodiesel from waste oil under acid [2], alkaline $[3,4]$ and enzyme $[5,6]$ catalysis. Waste cooking oils exhibit properties different than those of refined and crude oils. The high temperatures of particular cooking processes and the water from the foods accelerate the hydrolysis of triglycerides and increase the FFA content in the oil. Acid catalysis is more efficient when the amount of FFA in the oil exceeds 1\% [7]. Zheng et al. [2] studied the kinetics of acidcatalyzed transesterification of waste frying oil in excess of methanol to produce biodiesel. They concluded that it is a pseudo-first-order reaction, provided that the methanol/oil molar ratio is close to $250: 1$ at $70{ }^{\circ} \mathrm{C}$ or in the range of $74: 1$ $250: 1$ at $80{ }^{\circ} \mathrm{C}$. Under these conditions, high yield of biodiesel $(99 \pm 1 \%)$ can be obtained at a stirring rate of 400 rpm, using a feed molar ratio oil:methanol:acid of 1:245:3.8. Though acid-catalyzed transesterification is insensitive to FFA in the feedstock, it requires longer reaction time and higher temperature. Many researchers recommend using acid-catalysis as pretreatment step followed by alkalinecatalyzed step. Wang et al. [8] adopted this kind of two-step catalyzed process to prepare biodiesel from waste cooking oil. In the first step, FFAs of waste cooking oil were esterified with methanol catalyzed by ferric sulfate. In the second step, the triglycerides in the waste cooking oil were transesterified with methanol (methanol/oil molar ratio=6) catalyzed by $1.0 \mathrm{wt} \%$ potassium hydroxide at $65{ }^{\circ} \mathrm{C}$ for an hour. After this two-step catalysis process, the final product with $97.02 \%$ conversion of biodiesel was obtained. One 
alternative reaction conditions suitable for pilot-scale and industrial-scale biodiesel production purposes were found to be: Oil/alcohol molar ratio, 1:6; temperature, $55 \pm 1{ }^{\circ} \mathrm{C}$; $\mathrm{NaOH}$ amount, $1 \%$ (by the weight of the oil); stirring speed, $40 \mathrm{rpm}$; pressure, atmospheric; and reaction time, $60 \mathrm{~min}$.

This paper focused on the evaluation of the feasibility of using recycled canola oil as raw material for biodiesel synthesis through two-step reaction. The characterization results of biodiesel produced in this process showed that it can meet the requirements of ASTM D 6751, confirming the feasibility of using recycled canola oil as raw material to produce ASTM standard alternative fuel. Meanwhile, the properties of crude glycerol, such as flash point, moisture, ash, and glycerol content, were also characterized, which will benefit further biorefinery research underway.

\section{MATERIALS AND METHODOLOGY}

\subsection{Materials and Equipments}

Recycled canola oil was obtained from local food processing plant. Potassium hydroxide flake, methanol (analytical reagent grade) and sulfuric acid (98\% pure) were procured from Fisher Scientific. The commercial adsorbent magnesol, used for the partial purification of recycled canola oil biodiesel, was obtained from The Dallas Group of America, Inc. (Jefferson City, USA). A flat bottom flask was used as laboratory scale reactor for the experimental studies in this work, and a hot plate with magnetic stirrer arrangement was used for heating the mixture in the flask. 831 KF Coulometer (Metrohm Company, Switzerland) was for moisture analysis; Closed-cup flash tester (Model K16200) was from Koehler instrument company, Inc. (NY, USA); Isotemp Muffle furnace (Model $182 \mathrm{~A}$ ) for ash analysis was from Fisher Sentific (USA); Centrifuge (Model HNS II) for water and sediment analysis was from Thermo Electron Corporation (MA, USA); NESLAB RTE-740 Digital Plus Refrigerated Bath for cold soak filtration analysis was from Thermo Scientific (NH, USA).

\subsection{Two-Step Biodiesel Production Process}

The moisture was measured by direct coulometric Karl Fischer titration according to ASTM D 6304. The moisture in the recycled canola oil was $0.2 \%$. The FFA for the recycled canola oil was $11 \%$. Since higher amount of FFA $(>1 \% \mathrm{w} / \mathrm{w})$ in the feedstock can directly react with the alkaline catalyst to form soaps, which are subject to form stable emulsions and thus prevent separation of the biodiesel from the glycerol fraction and decrease the yield, it is better to select two-stage catalysis: First acid-catalysis followed by alkaline catalysis (Fig. 1). In this study, sulfuric acid was chosen as acid catalyst and potassium hydroxide as alkaline catalyst.

\subsubsection{Acid-Catalyzed Esterification}

$600 \mathrm{ml}$ recycled canola oil was precisely quantitatively transferred into the reaction flask and preheated by the hot plate to the desired reaction temperature before the reaction started. The sulfuric acid-methanol solution was prepared freshly and heated to the reaction temperature. Then the methanolic solution was added to the recycled canola oil in the reaction flask, and at this point, the measurement of reaction time was started. After the required reaction time, the reaction mixture was poured into the separatory funnel and was allowed to settle for 1 hour. The excess methanol together with sulfuric acid and impurities was moved to the top layer after settlement. The lower layer (oil phase) was ready for alkali-catalyzed transesterification.

\subsubsection{Alkali-Catalyzed Transesterification}

The esterified recycled canola oil (lower oil phase) was transferred to the reaction flask and preheated to the desired reaction temperature. Calculated amount of potassium hydroxide was dissolved in the methanol required. The solution of $\mathrm{KOH}$ and methanol was preheated to the reaction temperature. Finally the methanolic solution was added to the esterified recycled canola oil. The transesterifcation was carried out on the hot plate and constant stirring speed was maintained. After reaction, the reaction mixture was poured into separatory funnel and allowed to settle overnight. After settlement, the top layer, methyl esters, was first washed with water and heated on the hotplate till it turned clear. Then magnesol treatment was performed. The lower layer, crude glycerol, was subject to further characterization.

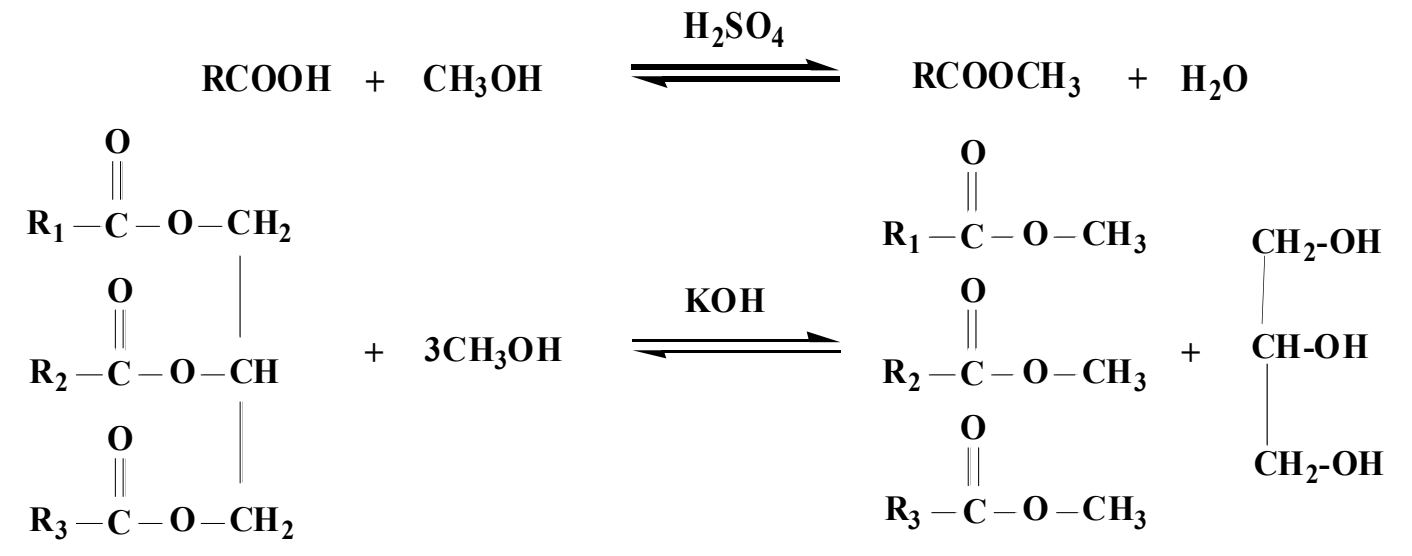

TRIGLYCERIDES METHANOL

BIODIESEL

GLYCEROL

Fig. (1). Mechanism of biodiesel synthesis by two-step catalyzed process. 


\subsection{Analytical Methods}

ASTM D 664 was used for FFA determination of recycled canola oil. The AOCS method Cc 17-95 was routinely used for soap determination in methyl esters derived from recycled canola oil. Karl-Fisher method (ASTM D 6304) was preferred to measure the moisture of recycled canola oil and its methyl ester.

An automatic 'cool on column' injection Gas Chromatograph (GC, Agilent Technologies, USA, 5890 Series II) was used for the determination of mono-, di- and triglycerides and free glycerol in accordance with ASTM D 6584. A capillary GC column (Restek, USA, Rtx-biodiesel column $(15 \mathrm{~m} \times 0.32 \mathrm{~mm}$ id $\times 0.10 \mu \mathrm{m}$ film $))$ was used in the apparatus. The temperature of flame ionization detector was $380{ }^{\circ} \mathrm{C}$. The initial GC oven temperature was kept at $50{ }^{\circ} \mathrm{C}$ for $1 \mathrm{~min}$, heated at $15^{\circ} \mathrm{C} / \mathrm{min}$ to $180^{\circ} \mathrm{C}$, and then heated at of $7{ }^{\circ} \mathrm{C} / \mathrm{min}$ to $230{ }^{\circ} \mathrm{C}$, finally heated at the ramp of 30 ${ }^{\circ} \mathrm{C} / \mathrm{min}$ to $380{ }^{\circ} \mathrm{C}$, at which it was kept for $10 \mathrm{~min}$. About $100 \mathrm{mg}$ of biodiesel sample was weighed into a $10 \mathrm{~mL}$ septa vial. Exactly $100 \mathrm{~mL}$ of each internal standard and MSTFA silylating agents were added to the vial. The vial was shaken and allowed to sit for $15 \mathrm{~min}$ at room temperature. Then, $8 \mathrm{~mL}$ of $\mathrm{n}$-heptane was added to the vial, which was then briefly shaken. A $1 \mu \mathrm{L}$ splitless injection volume was used. A calibration curve was generated from four standards (i.e., triolein (TG), diolein (DG), monoolein (MG), and glycerine) and two internal standards (i.e., 1,2,4-butanetriol for glycerine and 1,2,3-tricaproylglycerol (tricaprin) for glycerides). Each standard was injected three times at five different concentrations. The calibration curves of the standard solutions showed good linearity. (the standard solutions were a biodiesel package from Supelco Company)

Methanol content in recycled canola oil biodiesel was determined by headspace-GC in compliance with modified EN 14110. The analytical column, Rtx.-1, was from Restek $(30 \mathrm{~m} \times 0.32 \mathrm{~mm}$ id, $3 \mu \mathrm{m}$ film). The temperature for injector and FID was $160{ }^{\circ} \mathrm{C}$ and $250{ }^{\circ} \mathrm{C}$, respectively. The oven program was: $50{ }^{\circ} \mathrm{C}(1 \mathrm{~min})$ to $130{ }^{\circ} \mathrm{C}$ at $10{ }^{\circ} \mathrm{C} / \mathrm{min}$, final hold $0.5 \mathrm{~min}$. The sample and syringe were incubated at 50 ${ }^{\circ} \mathrm{C}$ for at least $15 \mathrm{~min}$ before analysis. The injected amount of the sample was $1 \mathrm{ml}$.

The recycled canola oil methyl esters (B100) produced in this study were characterized in relation to the technical limits established by ASTM D 6751, using the following methods: ASTM D 2709 for water and sediments, ASTM D93 for flash point, ASTM D 664 for acid number, ASTM D 6217 for cold soak filtration and ASTM D 6584 for free and total glycerin.

The by-product, crude glycerol, was also characterized. Glycerol content was determined according to AOCS Ea 694. Moisture content in glycerol was measured by KarlFisher. For ash content analysis, a given amount of sample was weighed into a crucible and burned in a furnace. After cooling, the ash content was calculated based on the residue on ignition. The M.O.N.G. (Material Organic Non Glycerin) is simply a calculation: $100 \%$ - glycerin $\%$ - ash $\%$ - water $\%=$ M.O.N.G. This includes all organics in the sample that are not glycerin. Methanol is part of M.O.N.G., along with fats, oils, and other organic solvents, etc.

\section{RESULTS AND DISCUSSION}

\subsection{Acid-Catalyzed Esterification and Alkali-Catalyzed Transesterification}

The molar ratio of alcohol to oil, catalyst concentration, reaction temperature and time are the main factors affecting acid-catalyzed esterfication. Of which, the molar ratio of alcohol to oil has a great effect on reducing FFA of vegetable oil. Molar ratios between 4.5:1 and 18:1 were reported in the literature [9]. In this study, 40:1 molar ratio of methanol to FFA was preferred and 5\% (based on FFA) sulfuric acid was added. The FFA in the recycled canola oil was decreased from $11 \%$ to $0.41 \%$. About $96.3 \%$ reduction was achieved after 1.5 hours acid-catalyzed esterification at $55^{\circ} \mathrm{C}$.

After esterfication, the transesterification of esterified recycled canola oil was carried out at $6 / 1$ molar ratio of methanol to oil in the presence of $1 \%(\mathrm{wt} / \mathrm{wt}$, based on oil) potassium hydroxide, plus the amount needed to neutralize the FFA [10-12].

\subsection{Purification Processes}

Purification processes, including washing and drying, are necessary since untreated biodiesel contains impurities, such as free glycerol, soap, free fatty acid, methanol, catalysts, metals and glycerides. The remaining unreacted methanol in the biodiesel has safety risks and can corrode engine components, the residual catalyst (sodium hydroxide) can damage engine components, and soap in the biodiesel can reduce fuel lubricity and cause injector coking and other deposits [13].

Traditional water wash has been widely used and proved to be effective to remove most impurities. However, there are many disadvantages: production cost increase due to waste water treatment; Emulsion formation when treating biodiesel from waste cooking oil due to soap formation [14]; Methyl esters loss due to retention in the water phase. Dry washes, the use of ion exchange resin, such as magnesol, can remove all these disadvantages. However, Berros et al. [15] found only water washing has purified biodiesel, direct from glycerol separation, to the requirements of EN 14214 Standard. Therefore, in this study, both water and magnesol washes are applied. First use two $20 \%$ (v/v, based on methyl ester layer) water wash followed by $0.5 \%(\mathrm{wt} / \mathrm{wt}$, based on methyl ester layer) magnesol wash.

\subsection{Fuel Properties of Recycled Canola Oil Biodiesel}

The physical and chemical properties of methyl esters from recycled canola oil are shown in Table $\mathbf{1}$.

\subsubsection{Water Content}

Biodiesel contaminated with water can cause engine corrosion or reaction with glycerides to produce soaps and glycerol. Water can also serve as media for bacteriological growth, leading to filter blockage. Due to these negative effects, ASTM D 6751 set the maximum allowable content of $0.05 \%$ for water in biodiesel. Water and sediment test showed no water in biodiesel produced from recycled canola oil. This can be attributed to the dry wash and drying process. 
Table 1. Characterization of Methyl Esters Obtained by Esterification and Transesterification of Recycled Canola Oil

\begin{tabular}{|c|c|c|c|c|}
\hline Property & Units & Method & Limits & Results \\
\hline Acid Number & $\mathrm{mg} \mathrm{KOH} / \mathrm{g}$ & D664 & $0.50 \max$ & 0.14 \\
\hline Flashpoint & ${ }^{\circ} \mathrm{C}$ & D93 (Closed cup) & $93 \mathrm{~min}$. & $>110$ \\
\hline Water and Settlement & vol.\% & D2709 & $0.05 \max$ & 0 \\
\hline Methanol content & $\%$ & EN 14110 & $0.2 \max$ & 0.038 \\
\hline Total Glycerin & mass $\%$ & D6584 & $0.24 \max$ & 0.13 \\
\hline Free Glycerin & $\operatorname{mass} \%$ & D6584 & $0.02 \max$ & 0.004 \\
\hline Visual Appearance & - & D4176 & Pass/fail & Pass \\
\hline Soap & ppm & AOCS Cc17-95 & report & 6 \\
\hline Moisture & ppm & D6304 & report & 235 \\
\hline Cold soak filtration & second & Annex to ASTM D6751 & 360 max. & 233 \\
\hline Kinematic viscosity, $40^{\circ} \mathrm{C}$ & $\mathrm{mm}^{2} / \mathrm{sec}$ & D445 & $1.9 \sim 6.0$ & 4.51 \\
\hline Sulfur (S 15 Grade) & ppm & D5453 & 15 max. & 5.9 \\
\hline Cloud point & ${ }^{\circ} \mathrm{C}$ & D2500 & Report & 1 \\
\hline Distillation, $90 \%$ recovery & ${ }^{\circ} \mathrm{C}$ & D1140 & $360 \max$ & 335 \\
\hline Oxidation stability & hours & EN14112 & $3 \mathrm{~min}$. & $>6$ \\
\hline Phosphorus & ppm & D4951 & 10 max. & 1 \\
\hline Calcium \& magnesium (combned) & ppm & EN14538 & $5 \max$. & 1 \\
\hline Sodium \& potassium (combined) & ppm & EN14538 & $5 \max$. & $<4$ \\
\hline
\end{tabular}

\subsubsection{Acid Number}

The acid number, expressed as milligrams of potassium hydroxide per gram of sample, is a measure of acidic substance in the oil. It is used as a guide in the quality control as well as monitoring oil degradation during storage. Acid number of biodiesel is less than $0.5 \mathrm{mgKOH} / \mathrm{g}$ specified as the maximum value according to ASTM D 6751. As for biodiesel produced from recycled canola oil, the very low acid number, $0.14 \mathrm{mgKOH} / \mathrm{g}$ was obtained.

\subsubsection{Cold Soak Filtration}

The cold soak filtration test subjects the biodiesel to a soak period (16 hours) at cold temperatures $\left(4^{\circ} \mathrm{C}\right)$. After the 16 hours cold soak is completed, remove the samples and record the time of removal. Allow the sample to come to 68$72{ }^{\circ} \mathrm{F}$ without external heating. The sample should be filtered under a vacuum between 21 and 25 inches $\mathrm{Hg}$ using a 0.7 micron glass fiber filter with stainless steel support within 1 hour after reaching $68-72{ }^{\circ} \mathrm{F}$. There are two time limits for filtration to occur: For B100 for use throughout the year, the filtration time is 360 seconds or less; if the seller claims the post-blended $\mathrm{B} 100$ is fit for use in temperatures below $10^{\circ} \mathrm{F}$, the filtration time is 200 seconds or less. This test is a qualitative evaluation designed to replicate performance of the biodiesel in cold climates. Many factors may affect the cold soak filtration results, including the robustness of the process, the choice and quality of feedstock, and purification approaches. Based on the cold soak experiments (Table 2) conducted in our industrial lab before, the cold soak results are mostly affected by the soap value. The higher the soap value, the higher the cold soak filtration results. In addition, it was found that total glycerin can also negatively influence the cold soak filtration results. When the total glycerin is within the ASTM D 6751 standard limits, that is, less than $0.24 \%$, it will show no negative effect on the cold soak filtration results. In this study, recycled canola oil biodiesel has very low soap value and acceptable total glycerin, $6 \mathrm{ppm}$ and $0.20 \%$, respectively. Therefore, the fuel passed the cold soak filtration test. The result was 165 seconds, which exceeded the requirements of ASTM D 6217, 360 seconds.

Table 2. The Effect of Soap and Total Glycerin on the Cold Soak Filtration Test Results

\begin{tabular}{|c|c|c|c|}
\hline Sample & $\begin{array}{c}\text { Soap } \\
\text { (ppm) }\end{array}$ & $\begin{array}{c}\text { Total Glycerin } \\
\text { (\%) }\end{array}$ & $\begin{array}{c}\text { Cold Soak } \\
\text { (Seconds) }\end{array}$ \\
\hline \hline Biodiesel 1 & 160 & 0.28 & 866 \\
\hline Biodiesel 2 & 5 & 0.14 & 78 \\
\hline Biodiesel 3 & 45 & 0.19 & 271 \\
\hline Biodiesel 4 & 5 & 0.17 & 61 \\
\hline Biodiesel 5 & 26 & 0.09 & 81 \\
\hline
\end{tabular}

Note: biodiesel samples are from the same feedstock.

\subsubsection{Methanol Content}

Monitoring residual methanol in biodiesel is a safety issue since even small amounts of this material can reduce the flash point of the biodiesel. Moreover, residual methanol can affect fuel pumps, seals and elastomers, resulting in poor combustion properties. EN 14110 (2003) standard specifications require the methanol content to be less than $0.2 \%$ (wt/wt). GC analysis of recycled canola oil biodiesel indicates very low methanol content, $0.038 \%$. 


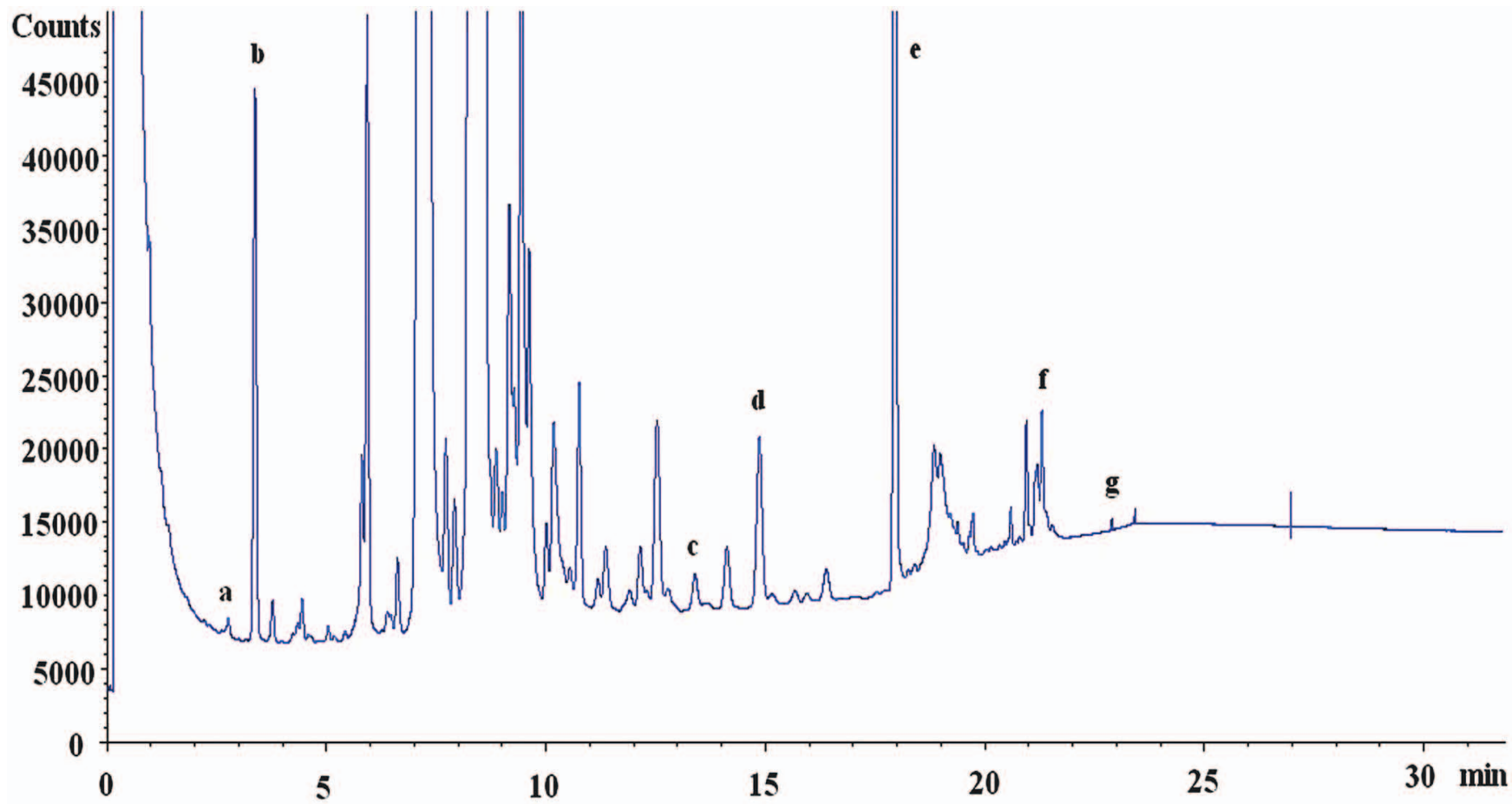

Fig. (2). GC chromatography of biodiesel from recycled canola oil. Lower case letters represent: a: free glycerol, b: butanetriol, c: monopalmitin, $\mathbf{d}$ : monoglyceride, e: tricaprin, f: diglycerides, $\mathbf{g}$ : triglycerides.

\subsubsection{Free and Total Glycerol}

Fuel with excessive free glycerol can increase aldehydes and acrolein emissions and will usually have a problem with glycerol settling out in storage tanks, creating a very viscous mixture that can plug fuel filters and cause combustion problems in the engine. Bound glycerol (mono-, di-, and triglycerides) is the indicator of the completeness of biodiesel production process. Lower bound glycerol indicates more complete transesterification process. GC chromatography showed in Fig. (2) identified the free glycerol, mono-, di-, and triglyceride peaks. Free and total glycerol contents are within the standard requirement, 0.01 and 0.21 , respectively.

\subsection{Characterizations of Crude Glycerol}

As the by-product of biodiesel production, glycerol has been received increasing attention recently. Many researchers focused on the developments in conversion of glycerol into value-added chemicals. Hence, the characterization of crude glycerol is very helpful for further biorefinery research. Table 3 listed the characterization results of crude glycerol obtained from recycled canola oil biodiesel production. The low flashpoint $\left(25^{\circ} \mathrm{C}\right)$ indicates there is much methanol in the crude glycerol, which may also explain the low glycerol content (39\%). Further steps, such as demethylation (to remove methanol in the crude glycerol) and acidulation (to remove soap in the crude glycerol) are necessary to be performed to purify the crude glycerol.
Table 3. Characterizations of Crude Glycerol

\begin{tabular}{|l|c|c|c|}
\hline \multicolumn{1}{|c|}{ Test } & Unit & Method & Result \\
\hline \hline Ash & $\%$ & - & 9 \\
\hline Flash point & ${ }^{\circ} \mathrm{C}$ & ASTM D93 ((closed cup) & 25 \\
\hline Moisture & $\%$ & Karl Fisher & 1.6 \\
\hline Glycerol content & $\%$ & AOCS Ea 6-94 & 39 \\
\hline MONG & $\%$ & - & 50.4 \\
\hline
\end{tabular}

\section{CONCLUSIONS}

In summary, due to its high FFA content, in this study two-step reaction was preferred to process recycled canola oil, that is, acid pretreatment followed by alkali-catalyzed transesterification. The first acid-catalyzed esterification step, carried out at $55^{\circ} \mathrm{C}$ for 1.5 hours at $40 / 1$ molar ratio of methanol to FFA and 5\% sulfuric acid concentration (v/v, based on FFA), reduced the FFA level from about $11 \%$ to $0.41 \%$. The second alkali-catalyzed transesterification step converted the esterified recycled canola oil into biodiesel under the following reaction conditions: $6 / 1$ molar ratio of methanol to oil; $1 \%$ potassium hydroxide; $55{ }^{\circ} \mathrm{C}$ and 1.5 hours. GC analysis based on the ASTM D6584 standard confirmed the production of high quality FAME from recycled canola oil. The recycled canola oil biodiesel obtained has fuel properties that completely met and exceeded ASTM D 6751 standard. Therefore, as a cheap 
feedstock, recycled canola oil can be potentially used as a raw feedstock for biodiesel production on a commercial scale. Furthermore, the properties of crude glycerol, including ash, moisture, glycerol content, MONG, and flashpoint, were characterized, which can facilitate the further biorefinery research for crude glycerol purification, promoting commercial biodiesel production and further development.

\section{ACKNOWLEDGEMENTS}

The authors wish to acknowledge Piedmont Biofuels Industrial for financing this research study.

\section{REFERENCES}

[1] Zhang, Y.; Dubé, M.A.; McLean, D.D.; Kates, M. Biodiesel production from waste cooking oil: 2. Economic assessment and sensitivity analysis. Bioresour. Technol., 2003, 90(3), 229-240.

[2] Zheng, S.; Kates, M.; Dubé, M.A.; McLean, D.D. Acid-catalyzed production of biodiesel from waste frying oil. Biomass Bioenergy, 2006, 30, 267-272.

[3] Encinar, J.M.; González, J.F.; Rodríguez-Reinares, A. Biodiesel from used frying oil. Variables affecting the yields and characteristics of the biodiesel. Ind. Eng. Chem. Res., 2005, 44, 5491-499.

[4] Felizardo, P.; Correia, M.J.; Raposo, I.; Mendes, J.F.; Berkemeier, R.; Bordado, J.M. Production of biodiesel from waste frying oils. Waste Manage., 2006, 26(5), 487-494.
[5] Watanabe, Y.; Shimada, Y.; Sugihara, A.; Tominaga, Y. Enzymatic conversion of waste edible oil to biodiesel fuel in a fixed-bed birreactor. J. Am. Oil Chem. Soc., 2001, 78(7), 703-707.

[6] Chen, G.; Ying, M.; Li, W. Enzymatic conversion of waste cooking oils into alternative fuel-biodiesel. Appl. Biochem. Biotechnol., 2006, 129-132, 911-921.

[7] Freedman, B.; Pryde, E.H.; Mounts, T.L. Variables affecting the yields of fatty esters from transesterified vegetable oils. J. Am. Oil Chem. Soc., 1984, 61(10), 1639-1643.

[8] Wang, Y.; Ou, S. Y.; Liu, P.Z.; Zhang, Z.S. Preparation of biodiesel from waste cooking oil via two- step catalyzed process. Energy Convers. Manage., 2007, 48, 184-188.

[9] Veljković, V.B.; Lakićević, S.H.; Stamenković, O.S.; Todorović, Z.B.; Lazić, M.L. Biodiesel production from tobacco (Nicotiana tabacum L.) seed oil with a high content of free fatty acids. Fuel, 2006, $85,2671-2675$.

[10] Meher, L.C.; Sagar, D.V.; Naik, S.N. Technical aspects of biodiesel production by transesterification-a review. Renewable Sustain. Energy Rev., 2006, 10(3), 248-268.

[11] Marchetti, J.M.; Miguel, V.U.; Errazu, A.F. Possible methods for biodiesel production. Renewable and Sustain. Energy Rev., 2007, 11(6), 1300-1311.

[12] Meher, L.C.; Dharmagadda, V.S.; Naik, S.N. Optimization of alkali-catalyzed transesterification of Pongamia pinnata oil for production of biodiesel. Bioresour. Technol., 2006, 97(12), 13921397.

[13] David Ryan, P.E. Biodiesel-A primer. Farm Energy Technical Note, 2004, 1-14.

[14] Canakci, M.; Gerpen, J.V. Biodiesel production from oils and fats with high free fatty acids. Trans. ASAE, 2001, 44(6), 1429-1436.

[15] Berrios, M.; Skelton, R.L. Comparison of purification methods for biodiesel. Chem. Eng., 2008, 144, 459-465. 